\title{
Three arrows models in the developing of new digital learning experiences
}

\author{
Pablo Riveros, Mika Tamura and Jin Tanaka
}

\begin{abstract}
The many challenges arising from COVID-19 have forced Japanese businesses and higher education to accelerate innovations and digital transformations. Japan is a well-known global leader in adopting innovative approaches with the use of advanced cutting-edge technologies, and education is not an exception. Digital learning and effective implementation of new pedagogies focused on distance learning, flexibility, and adaptation to innovative teaching practices are helping students and educators across Japan. As a result, Japan's traditional face- to-face lecture style is being rapidly transformed into a new Education 5.0, involving Cloud tools, correct use of learning management systems (LMS), web 4.0/5.0, and a wide range of other educational tools. Additionally, in our research and course design, we have adopted a new collaborative agile approach, including academic, industry expertise and teaching assistance facilitators. We identify challenges and opportunities through a case study that examines the design of a new course that incorporates agile collaboration and student perceptions after the adoption of this rapid and unexpected digital learning approach.
\end{abstract}

Keywords: COVID-19, society 5.0, digital learning, digital transformation, agile collaboration

\section{Introduction}

In recent years, higher education has experienced a significant shift encompassing greater internationalisation and student mobility, the growth of online and blended learning, and a rise in internet services on a global scale. The abundance of digital educational resources has triggered new pressures on institutions of higher education, such as the development of innovative curricula, educational programs and new academic pathways through digital learning (UNESCO). Digital learning is not a new practice in Japan's higher education system, yet despite the country's reputation as a high-tech nation, Japan has been slow to adopt digital learning in higher education; it is still common for lectures to be given in large lecture halls and for students to study with printed materials. Amidst the COVID-19 pandemic, many Japanese universities have been forced to delay the new semester by one month and create online learning curricula in a short period of time. Thus, despite its negative impacts, the coronavirus has offered a chance to update and upgrade educational innovation in Japan aligned to a future Japanese Society 5.0, which connects educational and digital technologies solutions and supports teachers and students to engage in a remote collaboration in the ever-expanding field of online learning. Through these advancements, Japan's traditional face-to-face lecture style is rapidly becoming a new Education 5.0.

Through a specific case study, this paper describes the implementation of an online Japanese language course that the authors, three researchers, developed by collaborating at the international level with three particular learning designs in mind. Inspired by the ancient Japanese legend of three arrows, we refer to them collectively as the 'three arrows model'.

\section{Theoretical framework}

This section provides the theoretical framework for the three learning designs - (1) agile digital learning, (2) content and language integrated learning (CLIIL), and (3) education for sustainable development; all of which aim to achieve the sustainable development goals (SDGs) (ESD for 2030) that we used to build an online Japanese language course. As aforementioned, we refer to them collectively as the 'three arrows model'.

\section{Agile digital learning}

We participated in an agile learning and virtual collaboration, incorporating our own 'three arrows model' based on a multidisciplinary team effort to further the swift adoption of innovative educational technology. These unprecedented times have reshaped and accelerated the use of e-learning experiences and have engendered novel ways of imparting and absorbing knowledge. 
According to the literature, agile methodologies are a group of software development techniques based on iterative and incremental development. The four major features fundamental to all agile methodologies are: (1) adaptive planning, (2) iterative, evolutionary development, (3) a brisk, flexible response to change, and (4) promoting communication (Begel \& Nagappan, 2007; Maher, 2009). Many software development companies have been quick to adopt agile approaches. Thus, agile methodologies are highly accepted in global developer communities and are speedily entering academia as well as the global business sector. We decided to take part in the agile digital approach 'given the growing interest in agile methods and thought it would be beneficial to frame agile instructional development in order to facilitate meaningful discussion' (Bratt, 2013). In addition, we hope to accelerate our design process and foster rapid innovation. Further, digital learning tool testing and the three arrows model demonstrate our collaboration (Figure 1).

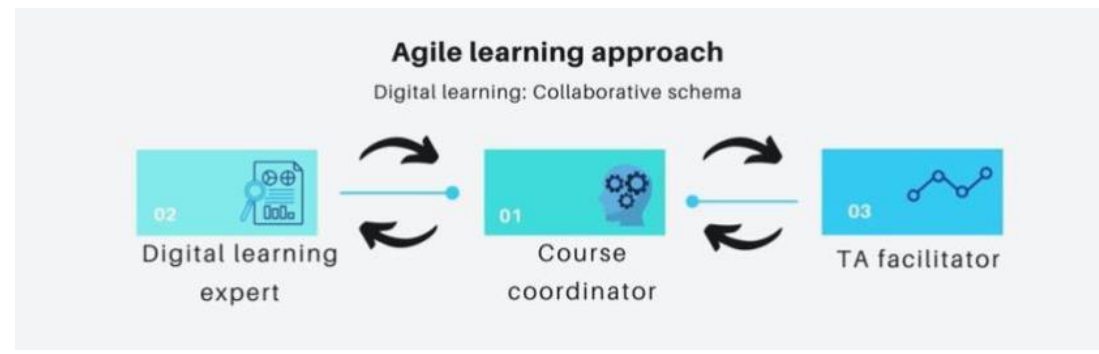

Figure 1: Teamwork via agile learning

CLIL

CLIL, mentioned earlier, "is a dual-focused approach in which an additional language is used to teach both content and language". That is, in the teaching and learning process, the focus is not solely on content, nor on language. Each is interwoven with the other, 'even if the emphasis is greater on one or the other at a given time' (Coyle, Hood, \& Marsh, 2010, p. 1). CLIL features four main components: content (subject matter), communication (language learning and use), cognition ([the] learning and thinking processes) and culture (developing intercultural understanding and global citizenship) (Coyle, Hood, \& Marsh, 2010).

ESD for 2030

ESD for 2030 is a new global framework on Education for Sustainable Development, which was adapted by UNESCO in 2019 and will officially be launched in 2021. ESD for 2030 aims to build education systems that support learners to be active contributors to a more sustainable world and develop a sense of responsibility to facilitate achievement of the 17 Sustainable Development Goals. The framework will focus on integrating ESD and the 17 SDGs into policies, learning environments, teachers and educators, youth, and communities (UNESCO).

\section{Case study - The three arrows model (An integrated and agile learning method)}

The case study outlined here is a Japanese language course for international students studying in the departments of engineering, agriculture and system information sciences at a large-scale, research-led national university in southern Japan. A total of nine students, including two graduate students and seven undergraduate students, enrolled in the course. Their nationalities varied: four were Chinese, with others from Vietnam, Mongolia, Thailand, Taiwan, and South Korea. The course is meant for students with an intermediate level of Japanese. However, students at the pre-intermediate and advanced levels also took this course.

The aim of this online Japanese language course was to prepare students for future specialised courses taught in Japanese. We designed it based on CLIL, whereby students explore a subject and a second language simultaneously, and ESD for 2030, whereby nine out of the United Nations' 17 SDGs are covered. Good practices are included to tackle challenges to be explored in the classroom. The course is content-focused; students are encouraged to think and learn in Japanese. Through peer-to-peer learning activities such as discussions, as well as peer reading and responses, students develop integrated Japanese language abilities. These include expanding vocabulary, improving reading skills and strengthening essay writing by working on assignments before and after each class.

\section{Findings and Discussion}


This section summarises the findings from the results and students' comments on the questionnaire, and then attempts an overview of findings centred on this research's main theme: designing the three arrows model for digital learning.

\section{Designing The three arrows model}

The three arrows model is a multidisciplinary, integrated, team-based method involving a course coordinator, a digital learning expert, and a teaching assistant, each of whom has different roles (Table 1).

Table 1. Three arrows model teaching project team

\begin{tabular}{|l|l|}
\hline Team Members & Roles in this course \\
\hline Course Coordinator & Is responsible for designing, planning and teaching a course. \\
\hline Digital Learning Expert & $\begin{array}{l}\text { Is responsible for various tasks related to the development and implementation of } \\
\text { hybrid learning and effective use of digital technology and digital learning data. }\end{array}$ \\
\hline Teaching Assistant & $\begin{array}{l}\text { Supports teachers by helping to supervise activities in the classroom or online, } \\
\text { engage students in learning activities and provide extra support } \\
\text { for complete tasks. }\end{array}$ \\
\hline
\end{tabular}

The underlying concept involves building swift Teaching and Learning (T\&L) support, working with experimental Edutech tools, developing learning content and engaging students through online experiences, with effective support and a pedagogical approach (Figure 2). We created the entire course from scratch in just six weeks. In this time, we designed online modules, engaged students through a visual LMS Moodle interface, planned video assignments, built new modules and redefined virtual assignments. To support effective, dynamic virtual learning compared to previous face-to-face class experiences, our teaching assistant oversaw an entire chat and virtual collaboration, engaged students through active Zoom participation, promoted new course ideas, held Padlet discussions and supported enhanced learner experiences.

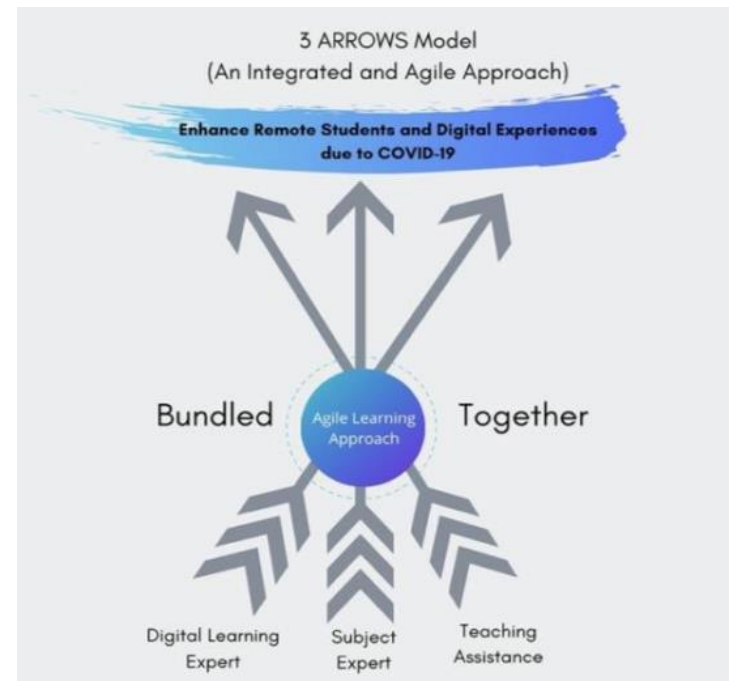

Figure 2: The three arrows model (an integrated, agile approach)

\section{Combining digital learning experiences and support}

We explored, piloted and applied various digital tools to encourage virtual learning, engage students in remote learning and foster student collaboration (Figure 3). 


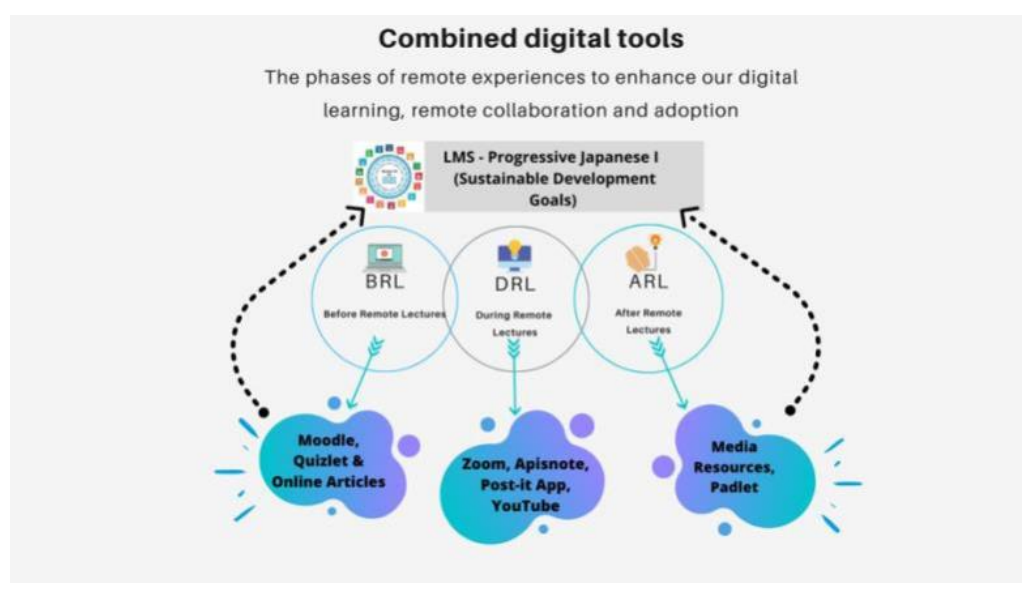

Figure 3: Digital learning tools as applied to our online experiences

We defined three simple online applications: before remote lectures (BRL), during remote lectures (DRL), and after remote lectures (ARL) (Table2).

Table 2. The phases of remote experiences to enhance our digital learning

\begin{tabular}{|l|l|}
\hline BRL & $\begin{array}{l}\text { Online Applications } \\
\text { virtual learning and build an inventory for the course content, e-assessments, } \\
\text { modules and class files. } \\
\text { Quizlet: Increase vocabulary and take part in discussions in Japanese. }\end{array}$ \\
\hline DRL & $\begin{array}{l}\text { Zoom video conferences: Provides a virtual space that functions as a classroom. } \\
\text { Zoom breakout rooms: Encourages students to converse with peers in Japanese, } \\
\text { which helps them to develop their vocabulary and boosts their participation. } \\
\text { Apisnote, Post-it app note: Instantly captures and shares notes with the student } \\
\text { team through online activities. } \\
\text { Media (YouTube, TEDx, Japanese digital media): Enables continuous learning } \\
\text { process, analysis of multimedia files and } \\
\text { discussions. }\end{array}$ \\
\hline ARL & $\begin{array}{l}\text { Padlet: Cloud board for building, sharing, publishing and enhancing effective } \\
\text { digital student collaboration. Allows posting and sharing of media files, group } \\
\text { projects and engagement in online discussions. }\end{array}$ \\
\hline
\end{tabular}

Summary of questionnaire results

At the end of the 14 lectures, the course coordinator collected students' feedback (through a questionnaire) to obtain their perspective, develop a realistic approach for remote implementation and identify areas for improvement.

- All 9 students who took this course were very satisfied with the content of this course.

- All 9 students who took this course thought the online CLIL classes were great.

- All 9 students who took this course thought their CLIL experiences were useful.

- 7 students found the activity for learning about SDGs related topics most helpful.

- 6 students found the activity for daily conversation practices, guest speakers' talks most helpful.

- 4 students found the activity for thinking about challenging problems and Peer-response most helpful.

Table 3. Students' preference for class activities 


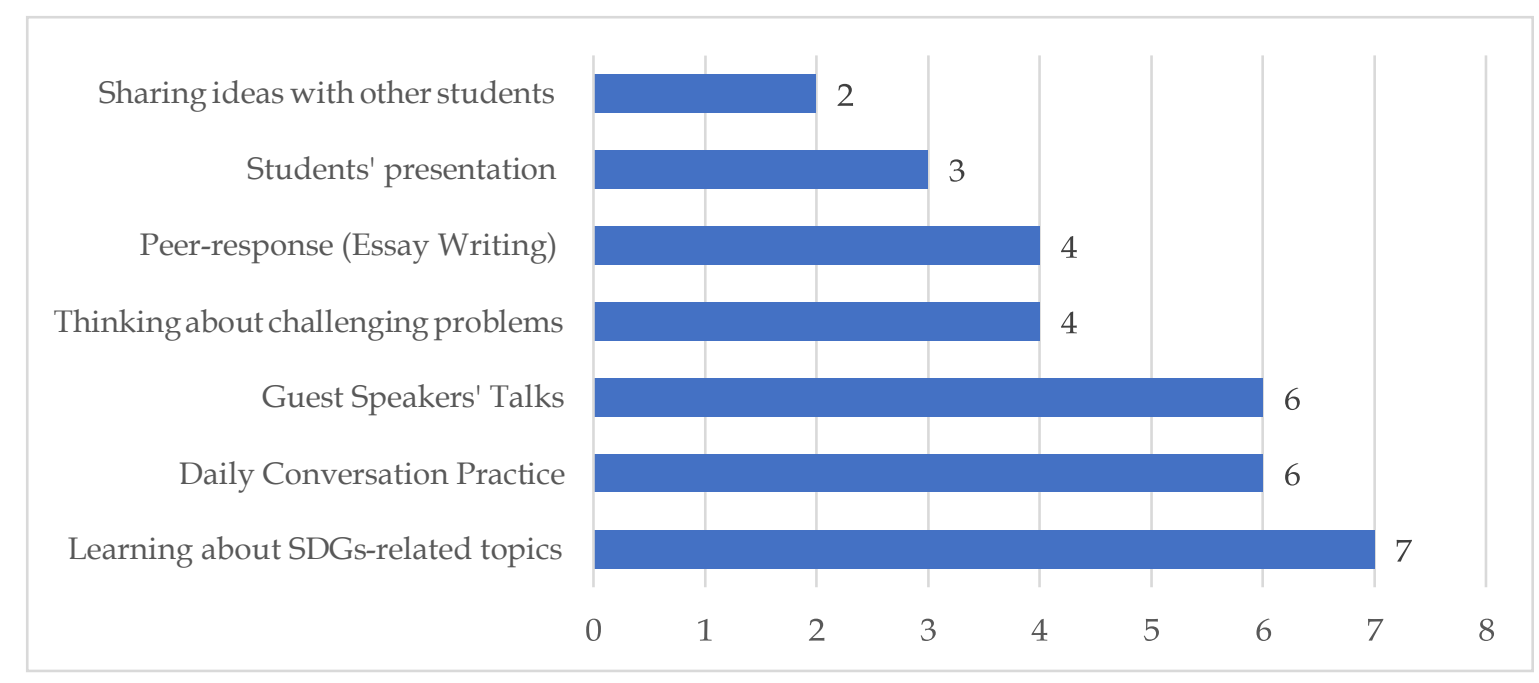

The results of the questionnaire showed that overall, students were satisfied with the content of this course and enjoyed learning through online CLIL courses through various activities using digital learning applications (Table 3). However, some students shared important insights on how their digital learning experiences might be improved.

Discussion is somewhat difficult to do online in my opinion. If there are other ways to discuss online, then I would like to try them. The peer response was really useful. I believe my essay improved after I received responses from others. However, I think it can be even better if we have few minutes to talk and get comments from each other during online lectures. (Student B)

I could guess since it was an online class, there was a limitation. It would be better if we could have an example answer (for example, answers by teachers or one of the students) before going into small groups and sharing ideas within them. Because we normally gave only short answers and sometimes wanted to say more. (Student C)

\section{Conclusion}

The adoption of the three arrows model has significantly challenged us as a team. The adaptability of virtual remote lectures and open, cross-team collaboration has helped us to create a new service model. These innovative challenges and the fast, agile use of new educational digital technologies, as well as the application of online learning frameworks, models and capabilities, have been an adaptive advantage during this global pandemic. Teamwork efficiency has been an advantage that relies on a stable digital environment, reinventing the traditional face-to-face context, and quickly acting to produce a fresh educational model to reshape the digital learning landscape. Further research will include learning about analytics and obtaining data from our digital platform, which is integrated into this course (such as Moodle, Zoom, and Padlet). These data will provide us with measurable results and information to optimise online experiences.

\section{References}

Begel, A., \& Nagappan, N. (2007, September). Usage and perceptions of agile software development in an industrial context: An exploratory study. In First International Symposium on Empirical Software Engineering and Measurement (ESEM 2007), 255-264. IEEE.

Bratt, S. (2013, June). Agile instructional development framework: strategies for increasing learner and instructional designer collaboration. In EdMedia+ Innovate Learning, Association for the Advancement of Computing in Education (AACE). 466-477.

Coyle, D., Hood, P., \& Marsh, D. (2010). CLIL Content and Language Integrated Learning. Cambridge: CUP.

Fostaty Young, S. and Wilson, R. J. (2000). Assessment and Learning: The ICE Approach. Winnipeg Portage and Main Press.

Maher, P. (2009, April). Weaving agile software development techniques into a traditional computer science curriculum. In 2009 Sixth International Conference on Information Technology: New Generations, IEEE 1687-688. 
Kumar, G., \& Bhatia, P. K. (2012). Impact of agile methodology on software development process. International Journal of Computer Technology and Electronics Engineering (IJCTEE), 2(4), 46-50.

Strielkowski, W. (2020), COVID-19 Pandemic and the Digital Revolution in Academia and Higher Education, COVID-19_Pandemic_and_the_Digital_Revolution_in_Academia_and_Higher_Education

UNESCO, Digital higher education, https://en.unesco.org/themes/higher-education/digital, Retrieved on 21 July 212020 .

UNESCO, ESD for 2030: What's next for Education for Sustainable Development?, https://en.unesco.org/news/esd-2030-whats-next-education-sustainable-development, Retrieved on 26 October 2020.

Riveros, P., Tamura, M., \& Tanaka, J. (2020). Three arrows models in the developing of new digital learning experiences. In S. Gregory, S. Warburton, \& M. Parkes (Eds.), ASCILITE's First Virtual Conference. Proceedings ASCILITE 2020 in Armidale (pp. 95-100). https://doi.org/10.14742/ascilite2020.0128

Note: All published papers are refereed, having undergone a double-blind peer-review process.

The author(s) assign a Creative Commons by attribution licence enabling others to distribute, remix, tweak, and build upon their work, even commercially, as long as credit is given to the author(s) for the original creation.

(c) Riveros, P., Tamura, M., \& Tanaka, J. 